\title{
1 Challenges and opportunities in population monitoring of cheetahs
}

3 Daniel W. Linden ${ }^{1 * \bullet}$, David S. Green ${ }^{2 \S^{*}}$, Elena V. Chelysheva ${ }^{3}$, Salim Mandela ${ }^{3}$, and Stephanie

4 M. Dloniak ${ }^{2}$

$5{ }^{1}$ NOAA National Marine Fisheries Service, Greater Atlantic Regional Fisheries Office,

6 Gloucester, MA 01930, USA

$7 \quad{ }^{2}$ Department of Integrative Biology, Michigan State University, East Lansing, MI, 45524, USA

$8 \quad{ }^{3}$ Mara-Meru Cheetah Project, Nairobi, Kenya

$10 *$ Corresponding author: daniel.linden@noaa.gov

$11 \S$ Current address: Institute for Natural Resources, Oregon State University, Corvallis, OR,

1297331, USA

13 These authors contributed equally.

15 Keywords: Acinonyx jubatus, cheetah, Masai Mara National Reserve, Mara-Serengeti

16 ecosystem, non-invasive sampling, population monitoring, spatial-capture recapture 


\section{Abstract}

18 Population monitoring is key to wildlife conservation and management but is challenging at the

19 spatial and temporal extents necessary for understanding changes. Non-invasive survey methods

20 and spatial capture-recapture (SCR) models have revolutionized wildlife monitoring by

21 providing the means to more easily acquire data at large scales and the framework to generate

22 spatially-explicit predictions, respectively. Despite the opportunities for improved monitoring,

23 challenges can remain in the study design and model fitting phases of an SCR approach. Here,

24 we used a search-encounter design with multi-session SCR models to collect spatially-indexed

25 photographs and estimate the changes in density of cheetahs between 2005 and 2013-2016 in the

26 Masai Mara National Reserve (MMNR) in southwestern Kenya. Our SCR models of cheetah

27 encounters suggested little change in cheetah density from 2005 to 2013-2016, though there was

28 some evidence that density fluctuated annually in the MMNR. The sampling period length (5 vs.

2910 months) and timing (early, late, full year) over which spatial encounters were included in the

30 modeling did not substantially alter inferences about density when sample sizes were adequate

31 ( $>20$ spatially distinct encounters). We estimated an average cheetah density of $\sim 1.2$

32 cheetahs $/ 100 \mathrm{~km}^{2}$, consistent with the impression that the MMNR provides important habitat for

33 cheetahs in Africa. During most years and seasonal periods, the spatial distribution of vegetation

34 greenness (a proxy for ungulate habitat quality) accounted for important variation in encounter

35 rates. The search-encounter design used here could be applied to other regions for the purposes

36 of cheetah monitoring. While snap-shot estimates of population size across time are useful for

37 wildlife monitoring, open population models could identify the mechanisms behind changes and

38 further facilitate better conservation and management decision making. 


\section{Introduction}

Population monitoring is key to wildlife conservation and management but is challenging at the spatial and temporal extents necessary for understanding changes (Ellis et al. 2014). Monitoring over space and time requires a feasible scheme and persistence in both dedication and resources to obtain adequate information. Low replication in either dimension reduces the capacity to explain observed patterns or test hypotheses about perturbation, limiting the value of the monitoring data for informing conservation and management decisions (Yoccoz et al. 2001). The monitoring challenge has been particularly acute for wide-ranging, cryptic species that occur at low densities, such as carnivores. These life history features have historically made data collection and analysis difficult and reduced the opportunities for robust inference about population dynamics at relevant spatial and temporal scales (Karanth et al. 2006).

Non-invasive survey methods (Long et al. 2008) and spatial capture-recapture (SCR) models (Borchers and Efford 2008, Royle et al. 2014) have revolutionized wildlife population monitoring by providing the means to more easily acquire data at large scales and the framework to generate spatially-explicit predictions, respectively. In an SCR model, the locations of individual encounters (e.g., photographs, genetic material) are used to determine centers of activity for each observed individual, providing spatial information on the number of total

56 individuals in the population and the probabilities of encountering them across the landscape. By formally linking the distributions of individuals and their movement ecology in a hierarchical framework, SCR models jointly estimate the ecological and observational processes that generate the spatial encounter data collected by large-scale monitoring designs, enabling robust inferences that are critical for conservation (Royle et al. 2018). These models have proven useful for estimating the density of wide-ranging carnivores, particularly in applications to large felids

62 including tigers Panthera tigris (Royle et al. 2009), jaguars Panthera onca (Sollmann et al. 2011), leopards Panthera pardus (Gray and Prum 2012) and cougars Puma concolor (Russell et al. 2012). Recently, the approach was illustrated using search-encounter surveys with African lions Panthera leo (Elliot and Gopalaswamy 2017) and cheetahs Acinonyx jubatus (Broekhuis and Gopalaswamy 2016). These applications have highlighted the potential of SCR as a monitoring tool, though rarely have studies spanned long enough timeframes to allow for

68 examining temporal changes in population size or density at large scales (e.g., Chandler and 69 Clark 2014). 
Despite the opportunities for improved monitoring, challenges can remain in the study design and model fitting phases of a spatial capture-recapture approach. Sampling efforts may not yield enough unique spatial locations per individual to enable model fitting (Becker et al. 2017), unless some type of auxiliary data is integrated (e.g., telemetry; Sollmann et al. 2013). Longer survey durations can be used to acquire more captures or encounters, at the expense of potentially violating assumptions regarding population closure (i.e., no births, deaths, immigrants/emigrants during sampling). The timing and duration of surveys will dictate the scope of the population being assessed, dependent on which individuals are available for sampling (e.g., residents vs. dispersers) and can meet assumptions of the observation process. Resource selection at one or more spatial scales can affect model inferences if not properly incorporated, particularly if it results in unmodeled heterogeneity in the encounter process (Royle et al. 2013, Linden et al. 2018). And small sample sizes, even when large enough to enable model fitting, may yet afford little power for accommodating relevant variation in one or more parameters which can reduce accuracy and precision of the resulting estimates (Sollmann et al. 2013). Most of these design and modeling considerations are important for any animal sampling and population estimation approach, and we note that explicitly modeling the sampling process does not necessarily obviate critical assumptions regarding how data were collected and what the data represent. For these reasons and others, it is prudent that researchers design robust monitoring schemes, use multiple lines of evidence, and temper any conclusions from monitoring data when making inferences that will guide conservation and management of large carnivore populations.

Here, we used a search-encounter design with SCR models (sensu Royle et al. 2011) to collect spatially-indexed photographs and estimate the changes in density of cheetahs between 2005 and 2013-2016 in the Masai Mara National Reserve (MMNR) in southwestern Kenya. Cheetahs are currently listed globally as "vulnerable" with a decreasing total population (Durant et al. 2015, Durant et al. 2017) and while much of the current cheetah range exists outside of protected areas the populations within represent important strongholds for cheetah conservation (Durant et al. 2017). Few long-term studies have empirically estimated how cheetah populations are faring over time (Chauvenet et al. 2011, Durant et al. 2011), or have illustrated how changing landscapes around protected areas may be influencing wildlife within reserve boundaries. 
Saharan Africa (Craft et al. 2015), and the Mara-Serengeti ecosystem is considered a stronghold for large carnivores in East Africa (Ogutu and Dublin 2002, Riggio et al. 2013). Yet, populations of wild herbivores in the MMNR have been declining over time (Ottichilo et al. 2000, Ogutu et al. 2009, Ogutu et al. 2011), livestock often graze within reserve boundaries and anthropogenic disturbance has altered the behaviors and population numbers of other large carnivores (Boydston et al. 2003, Kolowski and Holekamp 2009, Green et al. 2018a), and rangelands around the MMNR are rapidly shifting into a matrix of urbanization and agriculture (Lamprey and Reid 2004, Løvschal et al. 2017).

Broekhuis and Gopalaswamy (2016) recently provided a 2014 population estimate for cheetahs within the greater Mara using a similar survey and SCR modeling approach. We fit more extensive data from a multi-year survey effort (2005, 2013-2016) conducted during a

112 longer sampling window (10 months) with sample sizes that afforded additional model

113 complexity. In particular, we incorporated a resource selection function relating the probability 114 of encounter to annual variance in green vegetation (i.e., Normalized Difference Vegetation 115 Index [NDVI]) as an approximation to habitat quality for ungulate prey (Pettorelli et al. 2005, 116 Bro-Jorgensen et al. 2008). We hypothesized that cheetahs would be encountered more

117 frequently in areas with high variation where vegetation changed drastically across the year in

118 response to moisture (e.g., short grass), compared to low variance regions with relatively 119 constant conditions (e.g., riparian forest or bare ground). We also compared inferences between 120 5-month (both an early and late season) and 10-month sampling periods to explore tradeoffs in 121 the acquisition of encounters while trying to meet population closure assumptions.

122 Our earlier initial modeling efforts suggested a $>50 \%$ decline in cheetah density between 1232005 and 2013 (Green et al. 2014), but the population estimate by Broekhuis and Gopalaswamy 124 (2016) challenged that conclusion. Additional years of monitoring and subsequent modeling 125 indicate that the Mara cheetah population may exhibit annual fluctuations due to movement 126 between the MMNR, adjacent conservancies, and the Serengeti National Park, highlighting the 127 importance of conservation and management efforts in those areas surrounding the reserve. 


\section{Materials and Methods}

Study area and data collection

Our study took place in the $1510 \mathrm{~km}^{2}$ Masai Mara National Reserve in southwestern Kenya (Figure 1). The MMNR is predominantly comprised of open grassland interspersed with riparian areas, supporting a high density and diversity of resident herbivores, which are also

134 joined seasonally by migrant populations of wildebeest Connochaetes taurinus, zebra Equus quagga, and Thomson's gazelle Eudorcas thomsonii from the Serengeti National Park to the southwest and the Loita plains to the northeast (Bell 1971, Stelfox et al. 1986, Sinclair and

137 Norton-Griffiths 1995). The MMNR is bounded by the border with Tanzania and the Serengeti National Park to the south, and is surrounded in all other directions by community conservancies, pastoralist communities, small towns, and agricultural lands (Figure 1). There are no fences or barriers encompassing the MMNR, and wildlife regularly move beyond its political borders.

We systematically searched for cheetahs in the MMNR from January to October in 2005 and each year during 2013-2016 by dividing the MMNR into 6 sampling blocks roughly equal in size (Figure S1). Searches occurred between 0500 and 1900 h, during which time observers (1 or 2) drove throughout one block looking for cheetahs in a single vehicle, periodically stopping and scanning the surrounding landscape with binoculars (Caro 1994). Main roads were followed when convenient but considerable time was spent off-road to cover all accessible areas of each block; survey effort was calculated as the number of hours spent searching a block on a given date. When a cheetah was sighted, we drove within $50 \mathrm{~m}$ of an individual or group of individuals and photographed both sides of each animal and recorded geographic coordinates, sex and age class. We identified each individual using the distinct pelage and tail ring patterns (Caro and Durant 1991) and limited our modeling to adults.

153 by the USGS/EROS Data Center (https://earlywarning.usgs.gov/fews/). The data included $154250 \mathrm{~m}$ resolution grids with 10-day NDVI values observed across each year (36 for a given year) 155 for a region spanning most of East Africa. We calculated the standard deviation in NDVI value 156 within a given year to approximate the seasonal variation within a given grid cell. Notable 157 features that are apparent in every year include the vegetation along the Mara and Talek Rivers 158 (Figure S2). 
Similar to previous applications of spatial capture-recapture using unstructured searchencounter designs (Russell et al. 2012, Broekhuis and Gopalaswamy 2016), we divided our study area (the MMNR) into a grid with a sufficiently low resolution $(2-\mathrm{km} \times 2-\mathrm{km}$ cells) to create spatial encounter histories for individual cheetahs. We defined the number of encounters $y_{i j}$ for individual $i$ in grid cell $j$ as a Poisson-distributed random variable:

$$
y_{i j} \sim \operatorname{Poisson}\left(\lambda_{i j} g_{i j}\right)
$$

Here, $\lambda_{i j}$ is the mean encounter rate for an individual having its activity center $\left(\mathrm{s}_{i}\right)$ within a given grid cell, and $g_{i j}$ is a detection function describing how encounter rate decreases as the distance $\left(d_{i j}\right)$ increases between the location of an individual's activity center and the coordinates of grid cell $j$. We chose a Gaussian encounter probability model such that $g_{i j}=\exp \left(-d_{i j}{ }^{2} / 2 \sigma^{2}\right)$, where $\sigma$ is a scale parameter representing the standard deviation of a bivariate normal distribution used to approximate space usage (Royle et al. 2014). While sex is often used as a factor for describing variation in $\sigma$ (Sollmann et al. 2011, Broekhuis and Gopalaswamy 2016), our early model fitting did not indicate a difference between females and males or among years; $\sigma$ remained constant in our final model specification.

The mean encounter rate $\lambda_{i j}$ was modeled as a function of several variables specific to an individual and grid cell. We considered differences among years to account for potential factors related to observers and the space-use of individual cheetahs in a given year. We also considered two grid cell covariates for $\lambda_{i j}: 1$ ) the annual variance in NDVI for each year (standardized within the year to have mean $=0$ and unit variance); and 2) the log-transformed fraction of hours spent searching a grid cell, given its location within 1 of the 6 search blocks. We included quadratic functions for NDVI that were year-specific to accommodate resource selection by cheetahs in response to spatial-temporal differences in vegetation within the Mara across years. The effect of search effort was constrained similar to a Poisson offset, though we estimated a regression coefficient instead of assuming it was 1 . As such, we modeled the log-linear encounter rate $\left(\lambda_{i j}\right)$ as: a vector of year-specific coefficients for differences in encounter rates of individuals observed in 
190 later years $\left(\operatorname{yr}[i]=2013,2014,2015\right.$, or 2016); $\alpha_{2, y r}$ and $\alpha_{3, y r}$ are vectors of year-specific

191 coefficients for the linear and quadratic effects, respectively, of the variance in NDVI for each

192 grid cell in each year; and $\alpha_{4}$ is a coefficient describing the relationship between encounter rate

193 and search effort in a given grid cell and year. We considered encounters separated by $\geq 5$ days

194 to represent independent events with regards to individual movement and encounter probability

195 and, therefore, thinned $18-35 \%$ of the total encounters in a given year to help meet model

196 assumptions. Adult male cheetahs regularly form coalitions with other males (Caro and Collins

197 1987) and we observed them doing so in the MMNR ( $60 \%$ of male sightings involved

198 coalitions). Despite this, we treated each sighting as an independent observation given that

199 coalitions were sometimes observed to exhibit fission-fusion dynamics and that the

200 independence assumption for activity centers has been shown to be robust to departures (Reich

201 and Gardner 2014).

202 We modeled the distribution of latent activity centers using an inhomogeneous point

203 process (Borchers and Efford 2008) to estimate variation in cheetah density over the years. We

204 expanded the 2-km resolution grid of the MMNR to include a 20-km buffer (Figure S1), which

205 was large enough to ensure a negligible encounter probability at the edges (Royle et al. 2014);

206 we also excluded the northwest escarpment, which was likely to have restricted cheetah

207 movement (Broekhuis and Gopalaswamy 2016). The total state space, $S$, of the point process

208 therefore included 1,381 discrete grid cells for a total area of 5,524 $\mathrm{km}^{2}$. The intensity of the

209 point process (i.e., the expected density) within a grid cell $j$ in a given year was a log-linear

210 function:

$$
\log \left(\mathrm{E}\left(D_{j, \mathrm{yr}}\right)\right)=\beta_{0}+\beta_{1, \mathrm{yr}}
$$

212 Here, $\beta_{0}$ is the log-scale expected cheetah density in 2005 , while $\beta_{1, \text { yr }}$ is a vector of year-specific

213 regression coefficients that estimate differences in expected density in later years $(\mathrm{yr}=2013$,

214 2014, 2015, or 2016). Conditional on the expected density for the year in which an individual

215 was encountered $\left(\mathrm{yr}_{i}\right)$, the probability of an individual's activity center being located within a

216 given grid cell was defined as:

$$
\operatorname{Pr}\left(s_{i}=j \mid \boldsymbol{\beta}, \mathrm{yr}_{i}\right)=\frac{\mathrm{E}\left(D_{j, \mathrm{yr}}\right)}{\sum_{j} \mathrm{E}\left(D_{j, \mathrm{yr}}\right)}
$$


The marginal likelihood of the observations for each individual are then computed by integrating over all possible grid cells.

\section{Model fitting and sample period comparison}

We fit the model using the multi-session sex-structured SCR framework in the R package OSCR (Sutherland et al. 2016) which maximizes the Poisson-integrated likelihood (Borchers and Efford 2008) and provides maximum likelihood estimates of model parameters. In addition to the parameters previously described, OSCR allows for estimating a sex ratio $(\psi)$. Without specification of sex-specific parameters in the other SCR model components, estimates of $\psi$ are derived entirely from the observed sex ratios of encountered individuals during each session (here, session $=$ year).

We compared several sampling periods (early 5 months, full 10 months, late 5 months) to examine how differences in the observed data and parameter estimates affected population inferences. The early period spanned Jan-May and corresponded to a mostly hot and dry season that turns into long and heavy rains by May. The late period spanned Jun-Oct and corresponded to the cool season that follows the heavy rain season, during which widespread green vegetation supports a massive ungulate migration (Bell 1971, Sinclair and Norton-Griffiths 1995). This late period was similar to the 3-month sampling design (August-October) used by Broekhuis and Gopalaswamy (2016). The full 10-month sampling period spanned most of the year (Jan-Oct) and, while facilitating more observations and larger sample sizes of individuals and spatial encounters, was likely to violate the assumption of population closure to a greater degree than the 5-month periods. Aside from differences in the density estimates across time we were particularly interested in how other model parameters might change with variation in the number and type of spatial encounters, including the estimated NDVI relationships with encounter rate,

\section{Results}

245 Monitoring efforts resulted in $>7000$ hours spent searching for and recording observations of

246 cheetahs in the MMNR during 2005 and 2013-2016. The average number of hours searched

247 each year was 1443 (range: 1086-1694) for the 10-month sampling period, which split into 623

248 (range: 513-790) for the early 5-month period and 820 (range: 573-989) for the late 5-month 
period (Table 1). Compared to either 5-month period, the increased sampling effort for the full 10 months always resulted in greater numbers (within a given year) of unique individuals encountered $($ median across years: full $=32$, early $=20$, late $=23)$, total encounter events $($ full $=$ 101 , early $=40$, late $=60)$, and spatially distinct encounters $($ full $=58$, early $=18$, late $=28)$. The observed sex ratios were variable depending on the year and sampling period, though on a whole the median ratio was $1: 1$. We plotted the unique individuals encountered each year according to the midpoint ordinal date of their encounters, indicating the sampling period(s) in which they were observed (Figure 2). The patterns indicated similar ratios of females to males observed during all sampling period definitions.

The spatial capture-recapture models indicated similar patterns in density variation over time (Table 2-3; Figure 3), though fluctuations were mostly small relative to the uncertainty. The density estimates from 2005 had very large confidence intervals for the 5-month sampling periods due to small sample sizes. The full period density estimate (with 95\% CI) for 2005 was 1.62 (1.02-2.57) cheetahs/100 km². During 2013-2016, mean estimated density ranged from $0.60(0.34-1.10)$ cheetahs $/ 100 \mathrm{~km}^{2}$ in 2013 to $1.63(0.97-2.73)$ cheetahs $/ 100 \mathrm{~km}^{2}$ in 2014 , and estimates matched closely across sampling periods within a given year. Precision of the density estimates was better for the 10-month sampling period, particularly with regards to the coefficients of variation (Table 3). Regardless of the sampling period, density estimates with a $\mathrm{CV}<0.30$ could be achieved with $>20$ spatially distinct encounters (Figure 4 ).

The relationships between encounter rate and NDVI variance were variable across years and across sampling periods within a year (Table 2; Figure 5). For most years and sampling periods, the maximum encounter rates occurred at mid to high values of relative NDVI variance. The early period in 2016 was the primary exception, suggesting higher encounter rates for cheetahs in low variance areas during Jan-May. The hours spent searching a grid cell (given the survey block within which it was located) had a strong positive relationship with encounter rate, and average encounter rates were higher in later years (2013-2016) compared to 2005. The scale parameter of the half-normal distance function was much smaller for the early 5 -month period ( $\sigma$ $=4.9 \mathrm{~km}[4.4-5.4 \mathrm{~km}])$ compared to the late 5-month period $(\sigma=8.1 \mathrm{~km}[7.2-9.2 \mathrm{~km}])$ and the

277 full 10-month period $(\sigma=7.0 \mathrm{~km}[6.4-7.5 \mathrm{~km}])$. 
The sex ratios were estimated to be largely even across all years and sampling periods as none of the logit-scale estimates were significantly different from 0 (Table 2), suggesting that the probability of an individual being a male did not vary considerably from 0.50 .

\section{Discussion}

Effective wildlife population monitoring spans enough time and space to detect change or variation that may require further investigation or be targeted for management action. In addition to adequate spatial and temporal extents, the sampling intensity needs to produce enough observations to ensure reasonable precision from statistical models designed to estimate population parameters. Our spatial capture-recapture models of cheetah encounters suggested little change in cheetah density from 2005 to 2013-2016 in the Masai Mara National Reserve, though there was some evidence that density fluctuated annually in recent years. The sampling period length (5 vs. 10 months) and timing (early, late, full year) over which spatial encounters were included in the modeling did not substantially alter inferences about density when sample sizes were adequate (e.g., $\geq 20$ spatially distinct encounters). This suggests some flexibility in the design of search-encounter surveys for monitoring cheetahs over large landscapes.

We estimated an average cheetah density of $\sim 1.2$ cheetahs $/ 100 \mathrm{~km}^{2}$, consistent with the impression that the MMNR provides important habitat for cheetahs in Africa. Cheetah density varies extensively throughout the current species range, from 0.02 cheetahs $/ 100 \mathrm{~km}^{2}$ in areas of low productivity (Belbachir et al. 2015) to $>2$ cheetahs $/ 100 \mathrm{~km}^{2}$ in the highly productive Serengeti (Durant et al. 2011, Durant et al. 2017). Broekhuis and Gopalaswamy (2016) used a similar search encounter design with SCR modeling and estimated a mean cheetah density of $\sim 1.3$ cheetahs $/ 100 \mathrm{~km}^{2}$ in the MMNR and surrounding conservancies in 2014, which is consistent with our 2014 estimate from the late period $\left(1.37\right.$ cheetahs $/ 100 \mathrm{~km}^{2}$ ). Our additional indicated a relatively stable density in recent years (Chauvenet et al. 2011, Durant et al. 2011). If the density fluctuation we estimated during 2013-2016 represents a real ecological phenomenon, as opposed to sampling variability, then our comparison with 2005 is difficult to interpret, given that this single year could have represented either ebb or flow for the cheetah population. 
Therefore, it is actually unclear whether cheetah density has declined in the MMNR during the past $10+$ years. This uncertainty highlights the value of long-term monitoring programs, but also of monitoring designs that can estimate population size with useful precision. Our population modeling was limited to adult cheetahs and many individuals were encountered during only a portion of the year (Figure 2), therefore, population fluctuation in the MMNR is likely due to variable movement between the reserve and surrounding areas (e.g., Serengeti National Park). The magnitude of individual movements in cheetahs could make annual density an erratic statistic for an area the size of the MMNR $\left(1510 \mathrm{~km}^{2}\right)$, especially in the presence of non-resident, "floater" males (Caro 1994). Density estimation from SCR modeling is generally robust to transient individuals, though such movement dynamics could be explicitly modeled (Royle et al. 2016).

Based on the estimate of $\sigma$ from the distance function, the mean $95 \%$ space use or home range area ranged from $\sim 450$ to $\sim 1,200 \mathrm{~km}^{2}$ in the MMNR. Cheetah home ranges can be similar in size for males and females and overlap in areas where prey are non-migratory (Broomhall et al. 2003). In contrast, where ungulate prey are migratory, home ranges are comparatively larger with males forming small territories and females exhibiting roving behaviors (Caro 1994). Although there is a seasonal influx of migrant herbivores into the MMNR each year (Bell 1971, Stelfox et al. 1986, Sinclair and Norton-Griffiths 1995), resident herbivores are also present yearround in relatively high numbers. Thus, movements by cheetahs in the MMNR may be better predicted by interspecific competition with other large carnivores (Broekhuis et al. 2013) or the direct and indirect effects of people, rather than habitat suitability or prey populations. We caution any interpretation of the $95 \%$ space use approximation given the circular assumption of the bivariate normal distribution for $\sigma$ (Royle et al. 2014). In addition, cheetah space use has

332 been shown to be highly concentrated within a small portion of the home range ( $\sim 14 \%$ of the total area), even for individuals that otherwise occupy large areas (Marker et al. 2008).

Several differences between our study and that of Broekhuis and Gopalaswamy (2016; hereafter, $B \& G$ ) warrant discussion, given the similarity in our approaches to collecting and modeling spatial encounters of cheetahs in the Mara. First, B\&G modeled the daily encounter probability over 90 days of sampling, while we summed our encounters over the relevant sampling period (5 or 10 months) and treated the counts as a Poisson random variable; given the low rates of encounter, these choices should have had a negligible influence (Royle et al. 2014). 
Second, our definitions of effort differed and B\&G's approach was preferable: using GPS tracks to define exactly which areas were searched. We did not have GPS track records for 2005 and instead attempted to systematically search pre-defined sections (i.e., blocks) of the MMNR for various lengths of time; such a definition of effort is approximate at best, though blocks were searched thoroughly when visited. Third, we observed a fairly even sex ratio of cheetahs that remained constant over the 5 years of surveys and is consistent with previous research in the Mara-Serengeti (Kelly et al. 1998). The extremely skewed ratio observed by B\&G (F:M = 5:1) was potentially an artefact of a low sample size and short survey duration ( 3 months), though it should also be noted that most of their survey effort was in the conservancies to the north of the MMNR. Finally, B\&G estimated a difference in the scale parameter $(\sigma)$ between females and males; early data exploration here did not support such differences in our study, both given the observed maximum distances moved and preliminary estimates of $\sigma$ from models with sexspecific parameters. Despite these differences, the close similarity in cheetah density estimates provides empirical support to the robustness of SCR modeling (Royle et al. 2014).

Improvements to the design of our search-encounter survey could make the effort more efficient and useful in other parts of the species range. We thinned almost 1/3 of our observed cheetah encounters before fitting the SCR models because of uneven effort across space and time. Ideally, areas would be searched with regular periodicity to ensure that inferences regarding individual movement matched in temporal scale at all spatial locations. This is typically the case for other common methods of collecting spatial encounters (e.g., camera trapping), where traps are operated on regular intervals (Royle et al. 2014). The problem of sampling regularity would be most acute for transient individuals; for example, 5 consecutive days of effort in a given location could yield a very different collection of encounters than 5 days spread across several months. Uneven spatial sampling makes the interpretation of posterior 365 relegating the identification of "hot spots" (e.g., Broekhuis and Gopalaswamy 2016) to random 366 error. Finally, the ability to traverse the landscape and get close enough to individuals for high 367 quality photographs could limit the application of this survey to certain regions (e.g., protected 368 areas). While long-range camera lenses may provide expanded opportunities for monitoring, it 369 could still be difficult to clearly photograph both sides of every individual at great distances, 370 ultimately increasing identification uncertainty (Augustine et al. 2018). 
Other aspects of cheetah population ecology could be modeled with different or more complex analytical approaches to the individual encounter data we generated with the surveys. Our primary objective was a comparison between 2005 and 2013-2016, so we focused on understanding how best to estimate density within a given year (or seasonal period), while accommodating the sparse data from 2005. We hypothesized that individual space use and, thus, encounter probability would vary by habitat attributes and used NDVI variance as a proxy for ungulate habitat quality (Pettorelli et al. 2005, Bro-Jorgensen et al. 2008); in most years and seasonal periods, the spatial distribution of NDVI variance accounted for important variation in encounter rates. An open population model (Kendall et al. 1997) would allow for estimating survival and temporary emigration and potentially enable more comprehensive inferences than “snap-shot" density estimates (Harmsen et al. 2017). While open-population SCR models provide the opportunity to integrate spatial explicitness into estimation and prediction (e.g., Green et al. 2018b), the Bayesian frameworks typically used for fitting such models are notoriously slow and computationally demanding for complex spatiotemporal inferences. New approaches using maximum likelihood and hidden Markov models could provide promising alternatives (Glennie et al. 2017, Efford 2018b). Snap-shot estimates of population size across time are useful for wildlife monitoring, but understanding the mechanisms behind population changes can facilitate better conservation and management decision making (Harmsen et al.

\section{Acknowledgements}

We thank the Kenya Wildlife Service, the Office of the President of Kenya, the Senior Warden of the Masai Mara National Reserve, and Mr. Brian Heath for the permissions to carry out this research. We also thank Kay Holekamp for providing assistance in the field. SMD was supported by grants from the Lakeside Foundation, Mr. Paul L. Davies II, and Dalbit Petroleum Ltd. DSG was supported by a Graduate Research Fellowship from the National Science

\section{Authorship}

400 DWL, DSG, SMD, and EC designed the study. SMD, EC, and SM conducted the 401 fieldwork, and DWL completed the modeling. All authors contributed to the manuscript writing. 


\section{Data accessibility}

Data will be archived with Dryad Digital Repository.

\section{References}

Augustine, B. C., J. A. Royle, M. J. Kelly, C. B. Satter, R. S. Alonso, E. E. Boydston, and K. R. Crooks. 2018. Spatial capture-recapture with partial identity: An application to camera traps. Annals of Applied Statistics 12:67-95.

Becker, M. S., S. M. Durant, F. G. R. Watson, M. Parker, D. Gottelli, J. M'soka, E. Droge, M. Nyirenda, P. Schuette, S. Dunkley, and R. Brummer. 2017. Using dogs to find cats: detection dogs as a survey method for wide-ranging cheetah. Journal of Zoology 302:184-192.

Belbachir, F., N. Pettorelli, T. Wacher, A. Belbachir-Bazi, and S. M. Durant. 2015. Monitoring rarity: the critically endangered Saharan cheetah as a flagship species for a threatened ecosystem. Plos One 10:e0115136.

Bell, R. H. 1971. A grazing ecosystem in the Serengeti. Scientific American 225:86-93.

Borchers, D. L. and M. G. Efford. 2008. Spatially explicit maximum likelihood methods for capture-recapture studies. Biometrics 64:377-385.

Boydston, E. E., K. M. Kapheim, H. E. Watts, M. Szykman, and K. E. Holekamp. 2003. Altered behaviour in spotted hyenas associated with increased human activity. Pages 207-219 in Animal Conservation forum. Cambridge University Press.

Bro-Jorgensen, J., M. E. Brown, and N. Pettorelli. 2008. Using the satellite-derived normalized difference vegetation index (NDVI) to explain ranging patterns in a lek-breeding antelope: the importance of scale. Oecologia 158:177-182.

Broekhuis, F., G. Cozzi, M. Valeix, J. W. McNutt, and D. W. Macdonald. 2013. Risk avoidance in sympatric large carnivores: reactive or predictive? Journal of Animal Ecology 82:1098-1105.

Broekhuis, F. and A. M. Gopalaswamy. 2016. Counting Cats: Spatially Explicit Population Estimates of Cheetah (Acinonyx jubatus) Using Unstructured Sampling Data. Plos One 11:e0153875.

Broomhall, L., M. Mills, and J. Du Toit. 2003. Home range and habitat use by cheetahs (Acinonyx jubatus) in the Kruger National Park. Journal of Zoology 261:119-128. 
Caro, T. 1994. Cheetahs of the Serengeti Plains: group living in an asocial species. University of Chicago Press.

Caro, T. and D. Collins. 1987. Male cheetah social organization and territoriality. Ethology $74: 52-64$.

Caro, T. and S. Durant. 1991. Use of quantitative analyses of pelage characteristics to reveal family resemblances in genetically monomorphic cheetahs. Journal of Heredity 82:8-14.

Chandler, R. B. and J. D. Clark. 2014. Spatially explicit integrated population models. Methods in Ecology and Evolution 5:1351-1360.

Chauvenet, A. L., S. M. Durant, R. Hilborn, and N. Pettorelli. 2011. Unintended consequences of conservation actions: managing disease in complex ecosystems. Plos One 6:e28671.

Craft, M. E., K. Hampson, J. O. Ogutu, and S. M. Durant. 2015. Carnivore communities in the greater Serengeti ecosystem. Pages 419-450 in A. R. E. Sinclair, K. L. Metzger, S. A. R. Mduma, and J. M. Fryxell, editors. Serengeti IV: sustaining biodiversity in a coupled human-natural system. The University of Chicago Press, Chicago, USA.

Durant, S., N. Mitchell, A. Ipavec, and R. Groom. 2015. Acinonyx jubatus. The IUCN Red List of Threatened Species 2015. e. T219A50649567.

Durant, S. M., M. E. Craft, R. Hilborn, S. Bashir, J. Hando, and L. Thomas. 2011. Long-term trends in carnivore abundance using distance sampling in Serengeti National Park, Tanzania. Journal of Applied Ecology 48:1490-1500.

Durant, S. M., N. Mitchell, R. Groom, N. Pettorelli, A. Ipavec, A. P. Jacobson, R. Woodroffe, M. Böhm, L. T. B. Hunter, M. S. Becker, F. Broekhuis, S. Bashir, L. Andresen, O. Aschenborn, M. Beddiaf, F. Belbachir, A. Belbachir-Bazi, A. Berbash, I. Brandao de Matos Machado, C. Breitenmoser, M. Chege, D. Cilliers, H. Davies-Mostert, A. J. Dickman, F. Ezekiel, M. S. Farhadinia, P. Funston, P. Henschel, J. Horgan, H. H. de Iongh, H. Jowkar, R. Klein, P. A. Lindsey, L. Marker, K. Marnewick, J. Melzheimer, J. Merkle, J. M'soka, M. Msuha, H. O'Neill, M. Parker, G. Purchase, S. Sahailou, Y. Saidu, A. Samna, A. Schmidt-Küntzel, E. Selebatso, E. A. Sogbohossou, A. Soultan, E. Stone, E. van der Meer, R. van Vuuren, M. Wykstra, and K. Young-Overton. 2017. The global decline of cheetah Acinonyx jubatus and what it means for conservation. Proceedings of the National Academy of Sciences 114:528-533. 
Efford, M. G. 2018a. Density surfaces in secr 3.1. http://www.otago.ac.nz/density/pdfs/secrdensitysurfaces.pdf Last Accessed 23 Feb 2018.

Efford, M. G. 2018b. openCR: Open Population Capture-Recapture. R package version 1.3.2. https://cran.r-project.org/package $=$ openCR.

Elliot, N. B. and A. M. Gopalaswamy. 2017. Toward accurate and precise estimates of lion density. Conservation Biology 31:934-943.

Ellis, M. M., J. S. Ivan, and M. K. Schwartz. 2014. Spatially explicit power analyses for occupancy-based monitoring of wolverine in the U.S. Rocky Mountains. Conservation Biology 28:52-62.

Glennie, R., D. L. Borchers, M. Murchie, B. J. Harmsen, and R. J. Foster. 2017. Open population maximum likelihood spatial capture-recapture. Submitted to Biometrics. http://hdl.handle.net/10023/11758.

Gray, T. N. E. and S. Prum. 2012. Leopard density in post-conflict landscape, Cambodia: Evidence from spatially explicit capture-recapture. Journal of Wildlife Management 76:163-169.

Green, D. S., L. Johnson-Ulrich, H. E. Couraud, and K. E. Holekamp. 2018a. Anthropogenic disturbance induces opposing population trends in spotted hyenas and African lions. Biodiversity and Conservation 27:871-889.

Green, D. S., D. W. Linden, E. V. Chelysheva, and S. M. Dloniak. 2014. Estimating changes in cheetah density and distribution in the Mara-Serengeti ecosystem with spatial capturerecapture (SCR). The Wildlife Society 21st Annual Conference, Pittsburgh, PA. DOI: 10.13140/RG.2.2.34678.86086.

Green, D. S., S. M. Matthews, R. C. Swiers, R. L. Callas, J. Scott Yaeger, S. L. Farber, M. K. Schwartz, and R. A. Powell. 2018b. Dynamic occupancy modelling reveals a hierarchy of competition among fishers, grey foxes and ringtails. Journal of Animal Ecology 87:813824.

Harmsen, B. J., R. J. Foster, E. Sanchez, C. E. Gutierrez-González, S. C. Silver, L. E. T. Ostro, M. J. Kelly, E. Kay, and H. Quigley. 2017. Long term monitoring of jaguars in the Cockscomb Basin Wildlife Sanctuary, Belize; Implications for camera trap studies of carnivores. Plos One 12:e0179505. 
Karanth, K. U., J. D. Nichols, N. S. Kumar, and J. E. Hines. 2006. Assessing tiger population dynamics using photographic capture-recapture sampling. Ecology 87:2925-2937.

Kelly, M. J., M. K. Laurenson, C. D. FitzGibbon, D. A. Collins, S. M. Durant, G. W. Frame, B. C. Bertram, and T. Caro. 1998. Demography of the Serengeti cheetah (Acinonyx jubatus) population: the first 25 years. Journal of Zoology 244:473-488.

Kendall, W. L., J. D. Nichols, and J. E. Hines. 1997. Estimating temporary emigration using capture-recapture data with Pollock's robust design. Ecology 78:563-578.

Kolowski, J. and K. Holekamp. 2009. Ecological and anthropogenic influences on space use by spotted hyaenas. Journal of Zoology 277:23-36.

Lamprey, R. H. and R. S. Reid. 2004. Expansion of human settlement in Kenya's Maasai Mara: what future for pastoralism and wildlife? Journal of Biogeography 31:997-1032.

Linden, D. W., A. P. K. Sirén, and P. J. Pekins. 2018. Integrating telemetry data into spatial capture-recapture modifies inferences on multi-scale resource selection. Ecosphere 9:e02203.

Long, R. A., P. MacKay, J. Ray, and W. Zielinski. 2008. Noninvasive survey methods for carnivores. Island Press, Washington, DC, USA.

Løvschal, M., P. K. Bøcher, J. Pilgaard, I. Amoke, A. Odingo, A. Thuo, and J.-C. Svenning. 2017. Fencing bodes a rapid collapse of the unique Greater Mara ecosystem. Scientific Reports 7:41450.

Marker, L., A. Dickman, M. G. Mills, R. Jeo, and D. W. Macdonald. 2008. Spatial ecology of cheetahs on north-central Namibian farmlands. Journal of Zoology 274:226-238.

Ogutu, J. and H. Dublin. 2002. Demography of lions in relation to prey and habitat in the Maasai Mara National Reserve, Kenya. African Journal of Ecology 40:120-129.

\section{Ogutu, J. O., N. Owen-Smith, H. P. Piepho, and M. Y. Said. 2011. Continuing wildlife} population declines and range contraction in the Mara region of Kenya during 19772009. Journal of Zoology 285:99-109.

Ogutu, J. O., H. P. Piepho, H. Dublin, N. Bhola, and R. S. Reid. 2009. Dynamics of MaraSerengeti ungulates in relation to land use changes. Journal of Zoology 278:1-14.

Ottichilo, W. K., J. De Leeuw, A. K. Skidmore, H. H. Prins, and M. Y. Said. 2000. Population trends of large non-migratory wild herbivores and livestock in the Masai Mara ecosystem, Kenya, between 1977 and 1997. African Journal of Ecology 38:202-216. 
Pettorelli, N., J. O. Vik, A. Mysterud, J. M. Gaillard, C. J. Tucker, and N. C. Stenseth. 2005. Using the satellite-derived NDVI to assess ecological responses to environmental change. Trends in Ecology \& Evolution 20:503-510.

Reich, B. J. and B. Gardner. 2014. A spatial capture-recapture model for territorial species. Environmetrics 25:630-637.

Riggio, J., A. Jacobson, L. Dollar, H. Bauer, M. Becker, A. Dickman, P. Funston, R. Groom, P. Henschel, and H. de Iongh. 2013. The size of savannah Africa: a lion's (Panthera leo) view. Biodiversity and Conservation 22:17-35.

Royle, J. A., R. B. Chandler, R. Sollmann, and B. Gardner. 2014. Spatial capture-recapture. Academic Press, Waltham, MA, USA.

Royle, J. A., R. B. Chandler, C. C. Sun, and A. K. Fuller. 2013. Integrating resource selection information with spatial capture-recapture. Methods in Ecology and Evolution 4:520-530.

Royle, J. A., A. K. Fuller, and C. Sutherland. 2016. Spatial capture-recapture models allowing Markovian transience or dispersal. Population Ecology 58:53-62.

Royle, J. A., A. K. Fuller, and C. Sutherland. 2018. Unifying population and landscape ecology with spatial capture-recapture. Ecography 41:444-456.

Royle, J. A., K. U. Karanth, A. M. Gopalaswamy, and N. S. Kumar. 2009. Bayesian inference in camera trapping studies for a class of spatial capture-recapture models. Ecology 90:32333244.

Royle, J. A., M. Kéry, and J. Guelat. 2011. Spatial capture-recapture models for searchencounter data. Methods in Ecology and Evolution 2:602-611.

Russell, R. E., J. A. Royle, R. Desimone, M. K. Schwartz, V. L. Edwards, K. P. Pilgrim, and K. S. McKelvey. 2012. Estimating abundance of mountain lions from unstructured spatial sampling. Journal of Wildlife Management 76:1551-1561.

Sinclair, A. R. E. and M. Norton-Griffiths. 1995. Serengeti: dynamics of an ecosystem. University of Chicago Press.

Sollmann, R., M. M. Furtado, B. Gardner, H. Hofer, A. T. A. Jacomo, N. M. Torres, and L. Silveira. 2011. Improving density estimates for elusive carnivores: Accounting for sexspecific detection and movements using spatial capture-recapture models for jaguars in central Brazil. Biological Conservation 144:1017-1024. 
554 Sollmann, R., B. Gardner, R. B. Chandler, D. B. Shindle, D. P. Onorato, J. A. Royle, and A. F.

555 O'Connell. 2013. Using multiple data sources provides density estimates for endangered

556 Florida panther. Journal of Applied Ecology 50:961-968.

557 Stelfox, J. G., D. G. Peden, H. Epp, R. J. Hudson, S. W. Mbugua, J. L. Agatsiva, and C. L.

558 Amuyunzu. 1986. Herbivore dynamics in southern Narok, Kenya. The Journal of

559 Wildlife Management 50:339-347.

560 Sutherland, C., J. A. Royle, and D. W. Linden. 2016. oSCR: Multi-Session Sex-Structured

$561 \quad$ Spatial Capture-Recapture Models. R package version 0.30.1.

562 https://github.com/jaroyle/oSCR.

563 Yoccoz, N. G., J. D. Nichols, and T. Boulinier. 2001. Monitoring of biological diversity in space

564 and time. Trends in Ecology \& Evolution 16:446-453. 


\section{Tables}

567 Table 1. Summary of monitoring effort and adult cheetah encounters in the Masai Mara National

568 Reserve during 2005 and 2013-2016. Results from the 3 sampling periods (early 5 months [Jan-

569 May], full 10 months [Jan-Oct], and late 5 months [Jun-Oct]) include the hours spent searching,

570 the number of unique individuals encountered (n) and broken down by sex (F/M), and the

571 number of encounter events (y). Spatially distinct encounters occur across $>1$ grid cell and by

572 definition involve recapture of an individual. For example, in 2005 there were 23 individuals

573 encountered during the early 5-month period but only 8 (4 female; 4 male) were encountered in

$574>1$ grid cell.

\begin{tabular}{|c|c|c|c|c|c|c|c|c|}
\hline \multirow[b]{2}{*}{ Months } & \multirow[b]{2}{*}{ Year } & \multirow[b]{2}{*}{ Hrs } & \multicolumn{3}{|c|}{ Total encounters } & \multicolumn{3}{|c|}{ Spatially distinct encounters } \\
\hline & & & $\mathrm{n}$ & $(\mathrm{F} / \mathrm{M})$ & $y>0$ & $\mathrm{n}$ & $(\mathrm{F} / \mathrm{M})$ & $\mathrm{y}>1$ \\
\hline \multirow[t]{5}{*}{5 (Jan-May) } & 2005 & 513 & 23 & $(12 / 11)$ & 34 & 8 & $(4 / 4)$ & 11 \\
\hline & 2013 & 790 & 12 & $(6 / 6)$ & 34 & 6 & $(3 / 3)$ & 18 \\
\hline & 2014 & 530 & 20 & $(10 / 10)$ & 40 & 13 & $(8 / 5)$ & 19 \\
\hline & 2015 & 705 & 24 & $(11 / 13)$ & 68 & 12 & $(6 / 6)$ & 39 \\
\hline & 2016 & 578 & 20 & $(12 / 8)$ & 41 & 7 & $(6 / 1)$ & 16 \\
\hline \multirow[t]{5}{*}{10 (Jan-Oct) } & 2005 & 1086 & 26 & $(14 / 12)$ & 47 & 14 & $(7 / 7)$ & 21 \\
\hline & 2013 & 1535 & 20 & $(10 / 10)$ & 73 & 13 & $(9 / 4)$ & 46 \\
\hline & 2014 & 1465 & 34 & $(14 / 20)$ & 112 & 26 & $(12 / 14)$ & 73 \\
\hline & 2015 & 1694 & 32 & $(13 / 19)$ & 142 & 19 & $(10 / 9)$ & 92 \\
\hline & 2016 & 1438 & 32 & $(17 / 15)$ & 101 & 22 & $(12 / 10)$ & 58 \\
\hline \multirow[t]{5}{*}{5 (Jun-Oct) } & 2005 & 573 & 11 & $(7 / 4)$ & 13 & 2 & $(0 / 2)$ & 2 \\
\hline & 2013 & 745 & 15 & $(10 / 5)$ & 39 & 8 & $(6 / 2)$ & 22 \\
\hline & 2014 & 935 & 30 & $(13 / 17)$ & 72 & 17 & $(5 / 12)$ & 39 \\
\hline & 2015 & 989 & 23 & $(10 / 13)$ & 74 & 12 & $(7 / 5)$ & 45 \\
\hline & 2016 & 860 & 27 & $(14 / 13)$ & 60 & 14 & $(9 / 5)$ & 28 \\
\hline
\end{tabular}


575 Table 2. Parameter estimates from the spatial capture-recapture models of adult cheetah

576 encounters in 2005 and 2013-2016 in the Masai Mara National Reserve, fit to data from the

577 early period (Jan-May), full period (Jan-Oct), and late period (Jun-Oct). Estimates are on the

578 scale of the appropriate link function, either $\log (\boldsymbol{\alpha}, \boldsymbol{\beta})$ or $\operatorname{logit}(\boldsymbol{\psi})$.

\begin{tabular}{|c|c|c|c|c|c|c|c|c|}
\hline \multirow[b]{2}{*}{ Process } & \multirow[b]{2}{*}{$\theta$} & \multirow[b]{2}{*}{ Effect } & \multicolumn{2}{|c|}{ early (Jan-May) } & \multicolumn{2}{|c|}{ full (Jan-Oct) } & \multicolumn{2}{|c|}{ late (Jun-Oct) } \\
\hline & & & Estimate & $\mathrm{SE}$ & Estimate & $\mathrm{SE}$ & Estimate & $\mathrm{SE}$ \\
\hline \multirow[t]{17}{*}{ Encounter } & $\alpha_{0}$ & Intercept & -3.915 & 0.362 & -4.277 & 0.301 & -5.345 & 0.756 \\
\hline & $\alpha_{1,2013}$ & Year & 1.261 & 0.459 & 0.784 & 0.319 & 1.732 & 0.790 \\
\hline & $\alpha_{1,2014}$ & & 0.730 & 0.454 & 0.945 & 0.302 & 1.648 & 0.778 \\
\hline & $\alpha_{1,2015}$ & & 1.089 & 0.408 & 0.998 & 0.303 & 1.660 & 0.782 \\
\hline & $\alpha_{1,2016}$ & & 1.373 & 0.445 & 0.850 & 0.308 & 1.075 & 0.786 \\
\hline & $\alpha_{2,2005}$ & NDVI×Year & 1.284 & 0.485 & 0.366 & 0.232 & -0.560 & 0.386 \\
\hline & $\alpha_{2,2013}$ & & 1.167 & 0.393 & 0.709 & 0.252 & 0.621 & 0.344 \\
\hline & $\alpha_{2,2014}$ & & -1.684 & 0.491 & -0.157 & 0.155 & 0.254 & 0.196 \\
\hline & $\alpha_{2,2015}$ & & 0.961 & 0.335 & 0.775 & 0.219 & 0.580 & 0.297 \\
\hline & $\alpha_{2,2016}$ & & -0.413 & 0.247 & 0.143 & 0.148 & 0.823 & 0.298 \\
\hline & $\alpha_{3,2005}$ & $\mathrm{NDVI}^{2} \times$ Year & -0.920 & 0.397 & -0.369 & 0.225 & -0.245 & 0.382 \\
\hline & $\alpha_{3,2013}$ & & -0.675 & 0.392 & -0.731 & 0.284 & -0.879 & 0.442 \\
\hline & $\alpha_{3,2014}$ & & -1.569 & 0.458 & -0.609 & 0.174 & -0.636 & 0.230 \\
\hline & $\alpha_{3,2015}$ & & -0.377 & 0.228 & -0.257 & 0.145 & -0.130 & 0.187 \\
\hline & $\alpha_{3,2016}$ & & -0.408 & 0.219 & -0.127 & 0.125 & -0.236 & 0.211 \\
\hline & $\alpha_{4}$ & Effort & 0.874 & 0.151 & 0.703 & 0.130 & 0.691 & 0.149 \\
\hline & $\log (\sigma)$ & Dist. scale & 1.583 & 0.055 & 1.940 & 0.039 & 2.094 & 0.065 \\
\hline \multirow[t]{5}{*}{ Density } & $\beta_{0}$ & Intercept & -2.243 & 0.291 & -2.732 & 0.236 & -2.760 & 0.682 \\
\hline & $\beta_{1,2013}$ & Year & -1.474 & 0.418 & -0.668 & 0.328 & -0.791 & 0.735 \\
\hline & $\beta_{1,2014}$ & & -0.491 & 0.389 & -0.146 & 0.294 & -0.147 & 0.709 \\
\hline & $\beta_{1,2015}$ & & -0.867 & 0.358 & -0.415 & 0.295 & -0.659 & 0.714 \\
\hline & $\beta_{1,2016}$ & & -0.904 & 0.379 & -0.316 & 0.297 & -0.246 & 0.714 \\
\hline \multirow[t]{5}{*}{ Sex ratio } & $\psi_{2005}$ & $\operatorname{Pr}(\mathrm{M}) \times$ Year & -0.087 & 0.417 & -0.154 & 0.393 & -0.560 & 0.627 \\
\hline & $\psi_{2013}$ & & 0.000 & 0.577 & 0.000 & 0.447 & -0.693 & 0.548 \\
\hline & $\psi_{2014}$ & & 0.000 & 0.447 & 0.357 & 0.348 & 0.268 & 0.368 \\
\hline & $\psi_{2015}$ & & 0.167 & 0.410 & 0.379 & 0.360 & 0.262 & 0.421 \\
\hline & $\psi 2016$ & & -0.405 & 0.456 & -0.125 & 0.354 & -0.074 & 0.385 \\
\hline
\end{tabular}


579 Table 3. Mean estimates (with standard errors and coefficients of variation) of cheetah density

$580\left(\# / 100 \mathrm{~km}^{2}\right)$ from the spatial capture-recapture models of adult cheetah encounters in 2005 and

581 2013-2016 in the Masai Mara National Reserve, fit to data from the early period (Jan-May), full

582 period (Jan-Oct), and late period (Jun-Oct).

\begin{tabular}{|c|c|c|c|c|c|c|c|c|c|}
\hline \multirow[b]{2}{*}{ Year } & \multicolumn{3}{|c|}{ early (Jan-May) } & \multicolumn{3}{|c|}{ full (Jan-Oct) } & \multicolumn{3}{|c|}{ late (Jun-Oct) } \\
\hline & Mean & SE & $\mathrm{CV}$ & Mean & $\mathrm{SE}$ & $\mathrm{CV}$ & Mean & $\mathrm{SE}$ & $\mathrm{CV}$ \\
\hline 2005 & 2.65 & 0.77 & 0.29 & 1.63 & 0.38 & 0.24 & 1.58 & 1.08 & 0.68 \\
\hline 2013 & 0.61 & 0.18 & 0.30 & 0.83 & 0.19 & 0.23 & 0.72 & 0.20 & 0.28 \\
\hline 2014 & 1.62 & 0.43 & 0.26 & 1.41 & 0.25 & 0.18 & 1.37 & 0.28 & 0.20 \\
\hline 2015 & 1.12 & 0.24 & 0.21 & 1.07 & 0.19 & 0.18 & 0.82 & 0.18 & 0.22 \\
\hline 2016 & 1.07 & 0.27 & 0.25 & 1.19 & 0.22 & 0.18 & 1.24 & 0.27 & 0.22 \\
\hline
\end{tabular}


bioRxiv preprint doi: https://doi.org/10.1101/563122; this version posted February 28, 2019. The copyright holder for this preprint (which was not certified by peer review) is the author/funder, who has granted bioRxiv a license to display the preprint in perpetuity. It is made available under aCC-BY 4.0 International license.

\section{Figures}

584 Figure 1. The location of cheetah monitoring in the Masai Mara National Reserve (MMNR) in

585 southwestern Kenya $\left(35.125^{\circ} \mathrm{E}, 1.44^{\circ} \mathrm{S}\right)$. Other conservation areas (shaded) surround the

586 MMNR, including the Serengeti National Park in Tanzania to the south. Map data (C)

587 OpenStreetMap contributors, CC BY-SA.

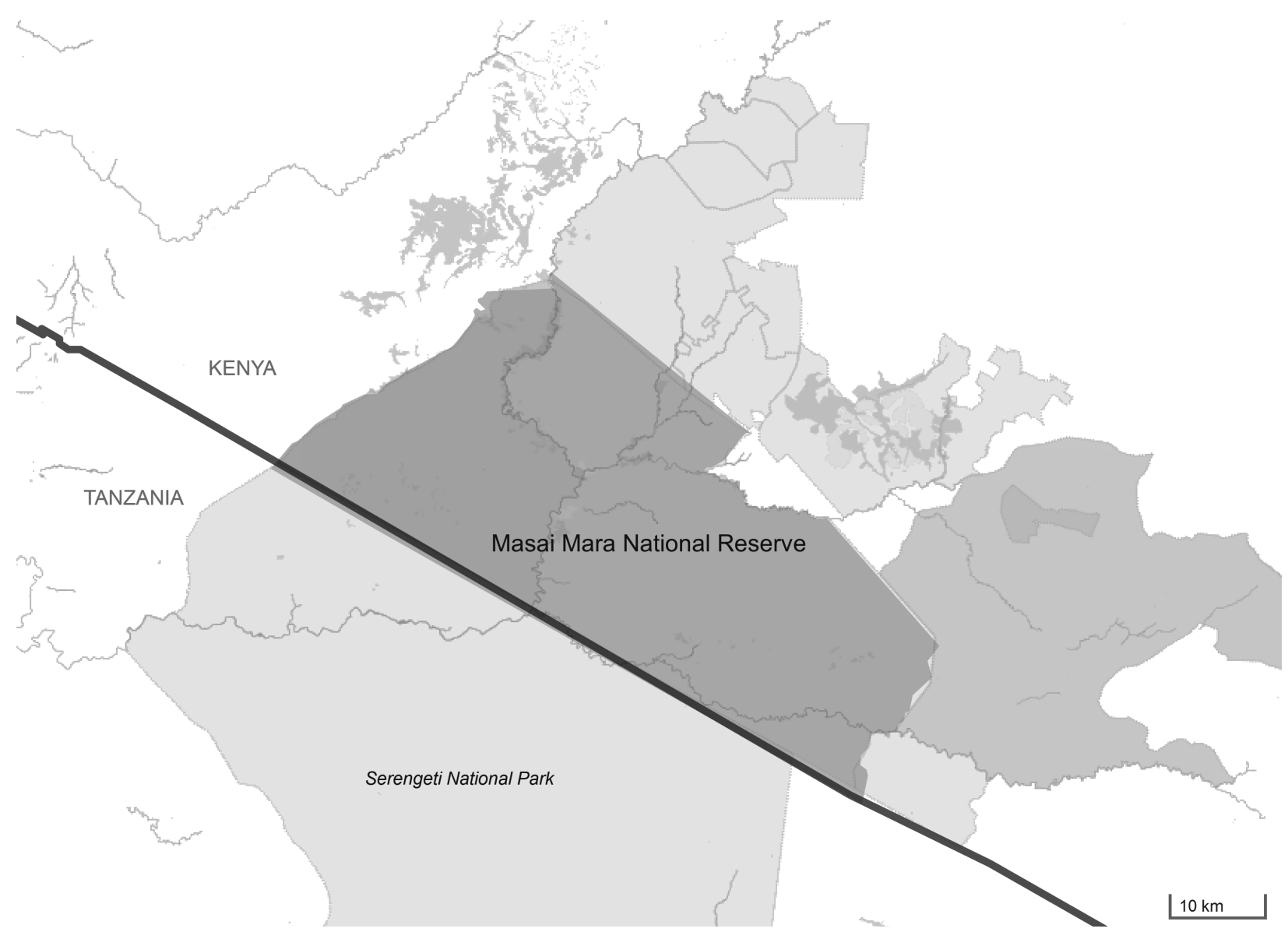


588 Figure 2. The midpoint ordinal date of encounter for each individual cheetah and the sampling 589 periods in which they were encountered in the Masai Mara during 2005 and 2013-2016. Note, 590 any individuals with encounters that spanned the full period (10 months) were included in the 591 spatial capture-recapture models for all 3 periods.

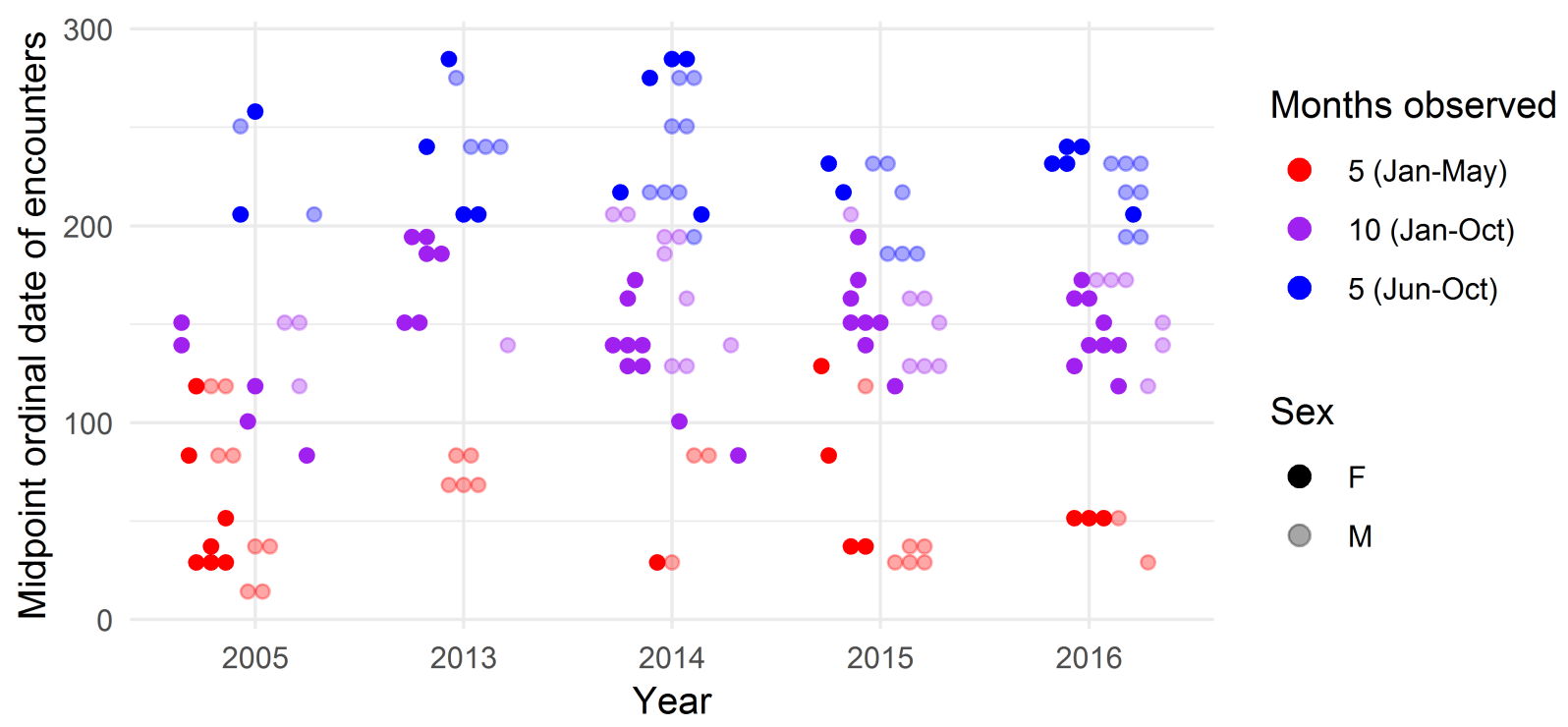


bioRxiv preprint doi: $\mathrm{https}$ //doi.org/10.1101/563122; this version posted February 28,2019 . The copyright holder for this preprint (which was not certified by peer review) is the author/funder, who has granted bioRxiv a license to display the preprint in perpetuity. It is made available under aCC-BY 4.0 International license.

592 Figure 3. Mean estimates (with 95\% CI) of cheetah density $\left(\# / 100 \mathrm{~km}^{2}\right.$ ) in the Masai Mara

593 National Reserve in 2005 and 2013-2016 from spatial capture-recapture models fit using 5

594 months (early and late periods) and 10 months of surveys.

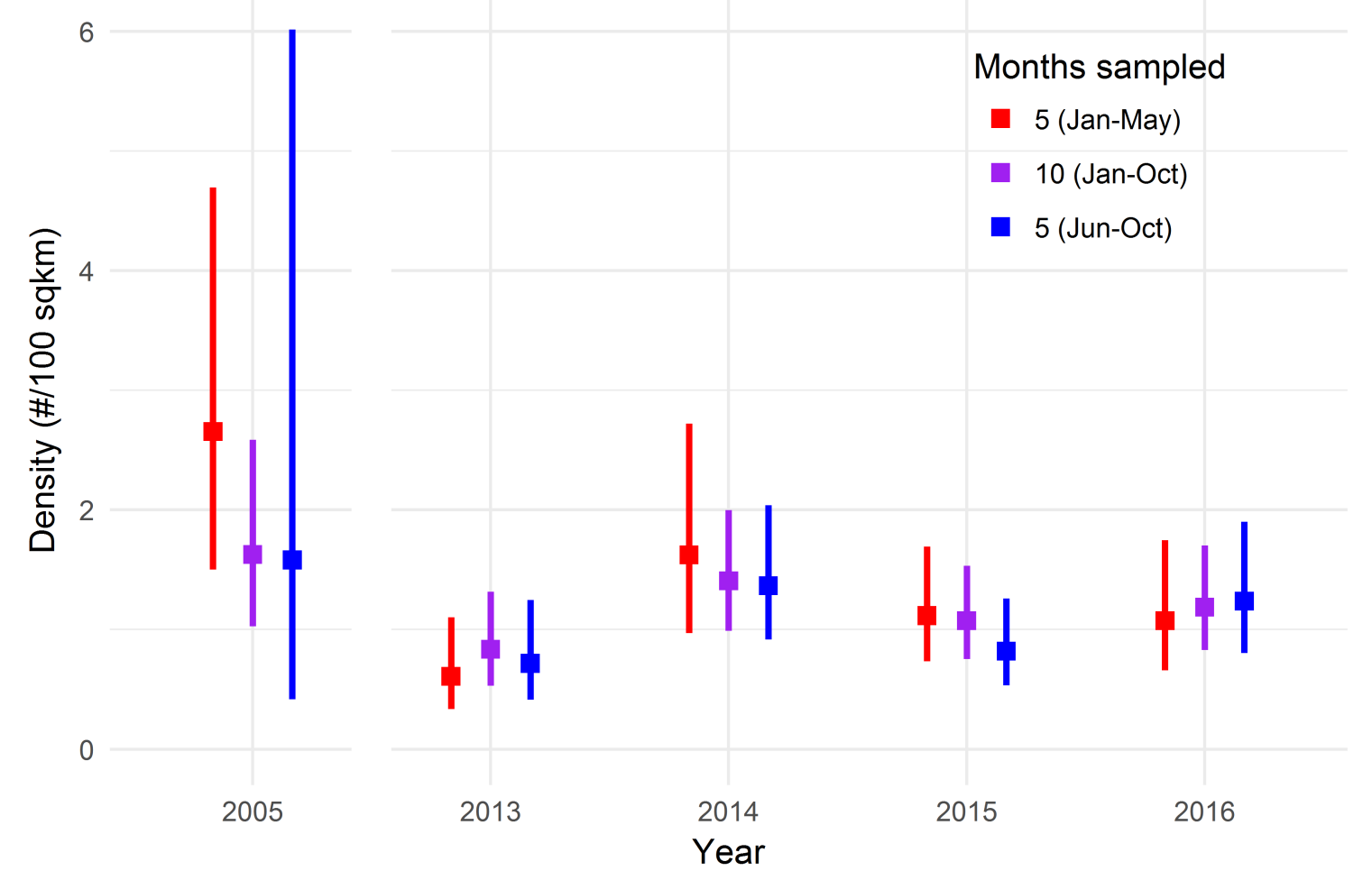


595 Figure 4. Relationship between number of spatially distinct encounters and coefficients of

596 variation (CVs) for density estimates from the spatial capture-recapture models. Spatially

597 distinct encounters occur across $>1$ grid cell and by definition involve recapture of an individual.

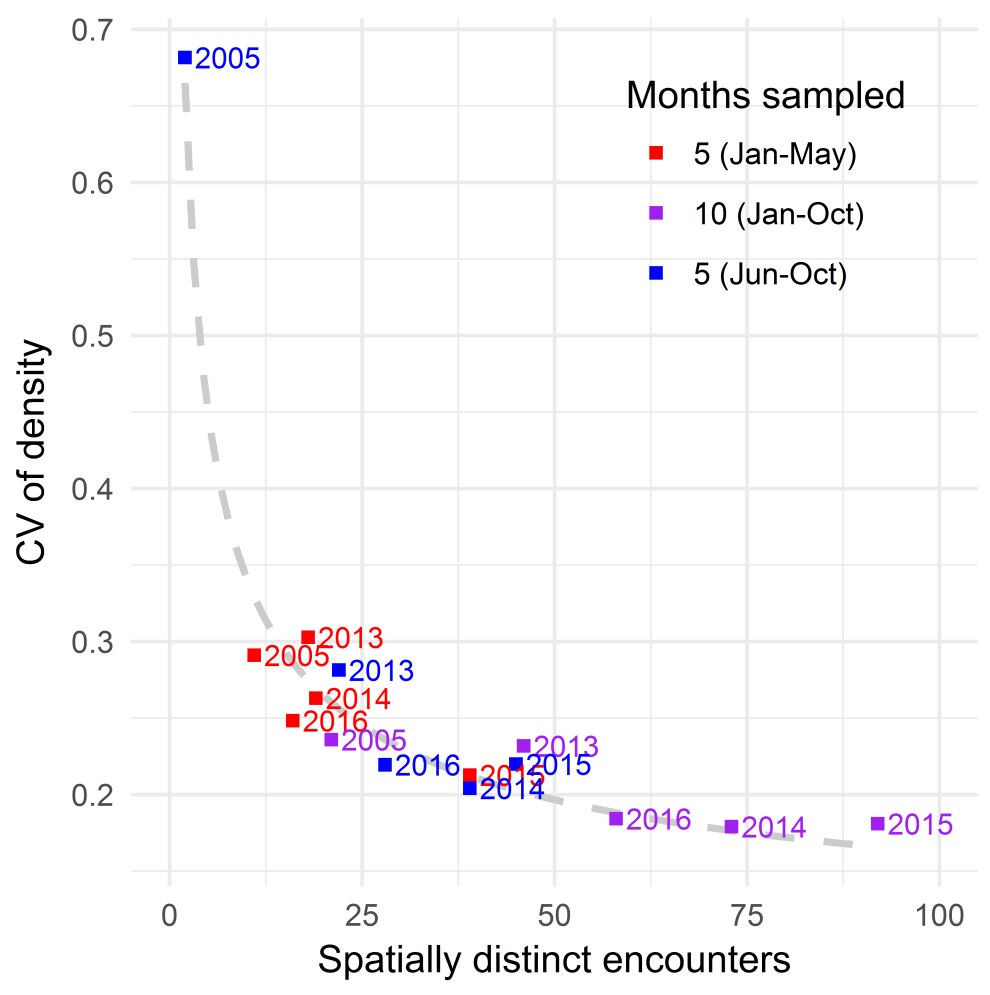


598 Figure 5. Predicted relationships (with 95\% CI) between NDVI variance and cheetah encounter

599 rate during 2005 and 2013-2016 from spatial capture-recapture models using 5 months (early

600 and late periods) and 10 months of surveys. Values for NDVI variance were standardized to

601 have mean 0 and unit variance within each year. Ticks at bottom indicate observed values at

602 pixel locations within the MMNR.

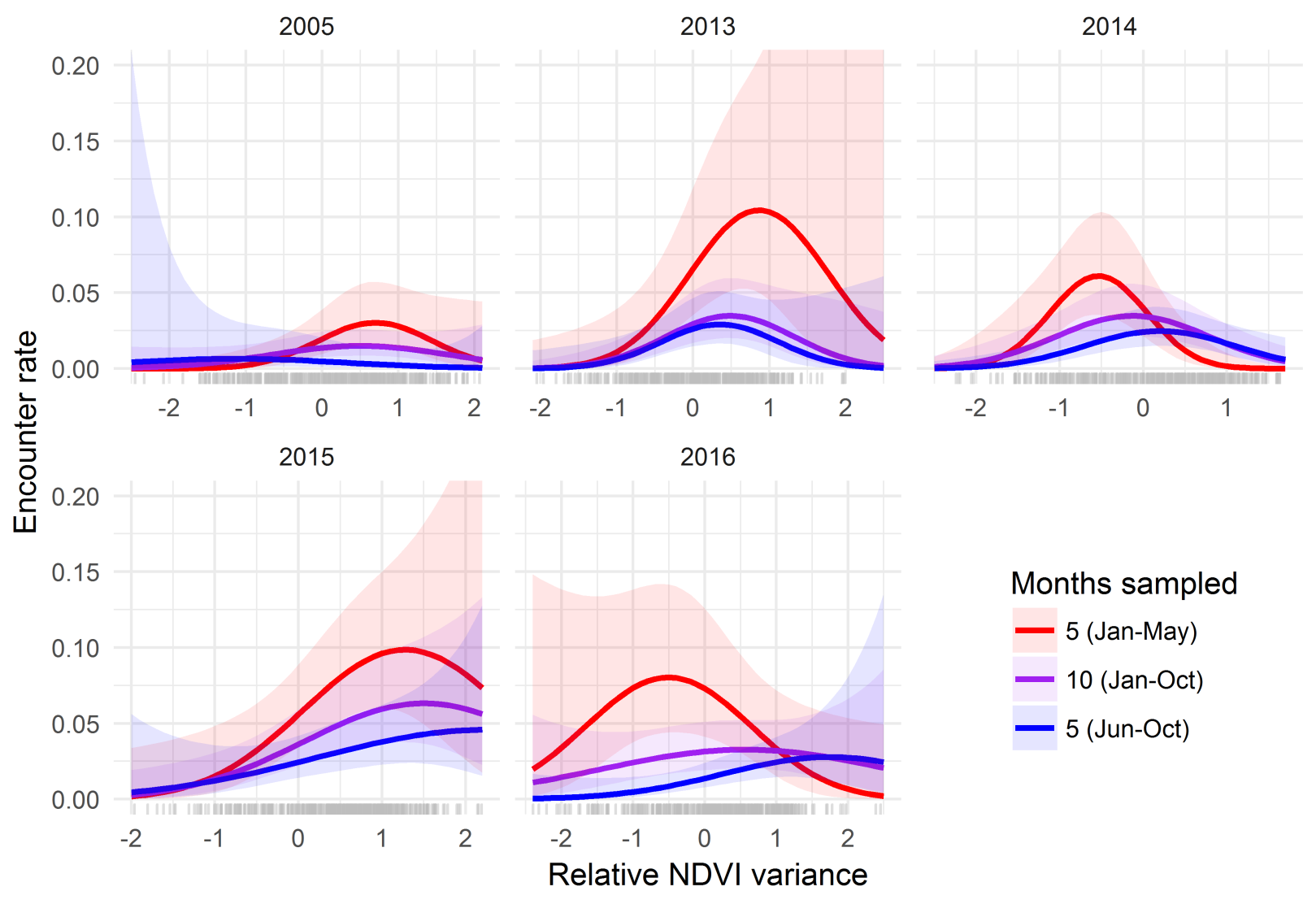


bioRxiv preprint doi: https://doi.org/10.1101/563122; this version posted February 28, 2019. The copyright holder for this preprint (which was not certified by peer review) is the author/funder, who has granted bioRxiv a license to display the preprint in perpetuity. It is made available under aCC-BY 4.0 International license.

\section{Supplements}

604 Figure S1. Grid cells illustrating state space used in the spatial capture-recapture models, with

605 delineations of blocks according to survey effort. Light gray cells occurred in areas not searched 606 but included as a buffer for population estimation.

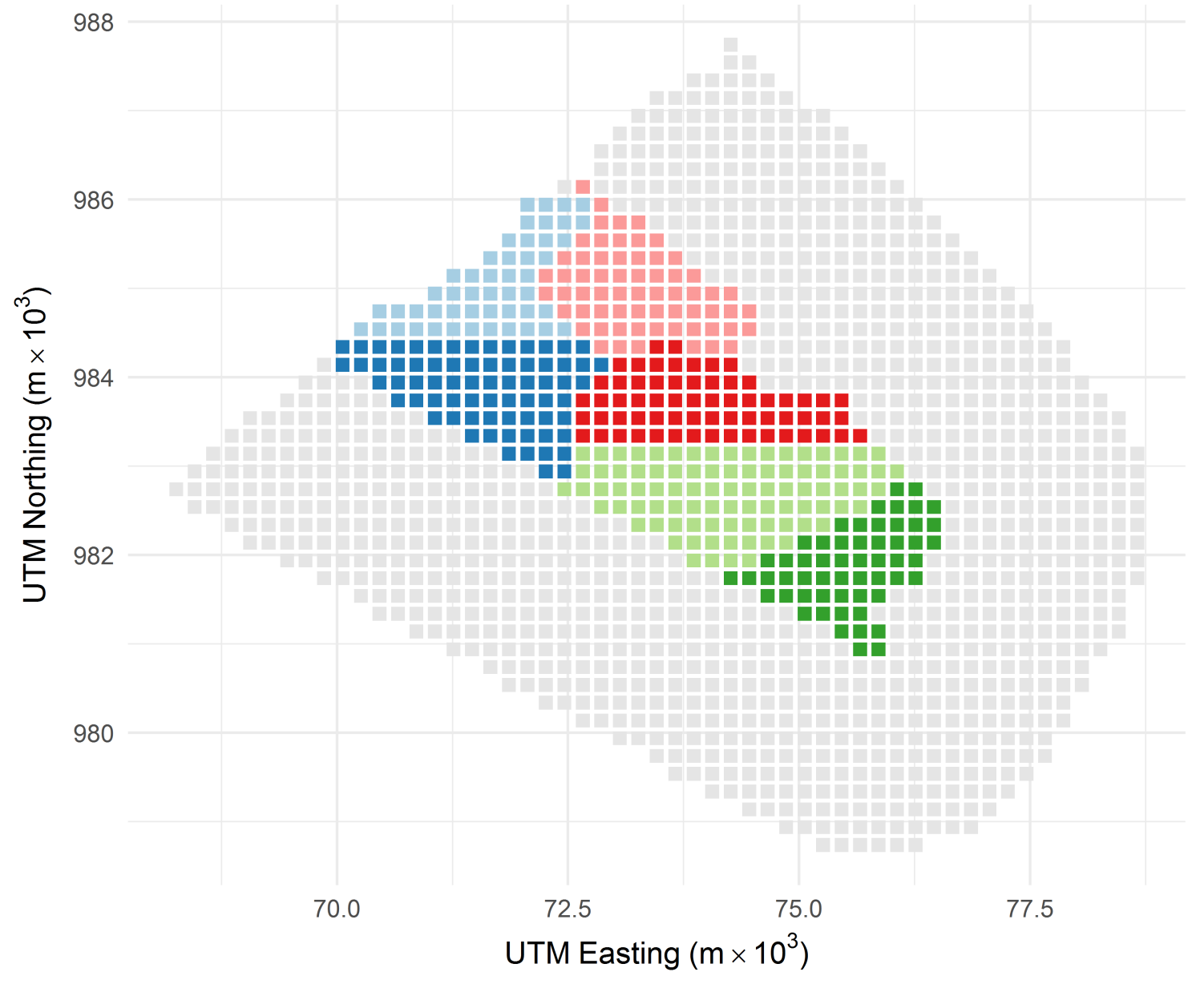


607 Figure S2. Spatial distributions of Normalized Vegetation Difference Index (NDVI) values in

608 each year that served as covariates for encounter probability in the spatial capture-recapture

609 models. Values represent the variance (standard deviation) in NDVI across the 36 satellite

610 images (10-day intervals at $250 \mathrm{~m}$ resolution) for a given year. NDVI values were mean

611 aggregated to the 2-km grid cells and standardized within each year to have mean of zero and

612 unit variance. Satellite images acquired from the Famine Early Warning System Network

613 hosted by the USGS/EROS Data Center (https://earlywarning.usgs.gov/fews/).
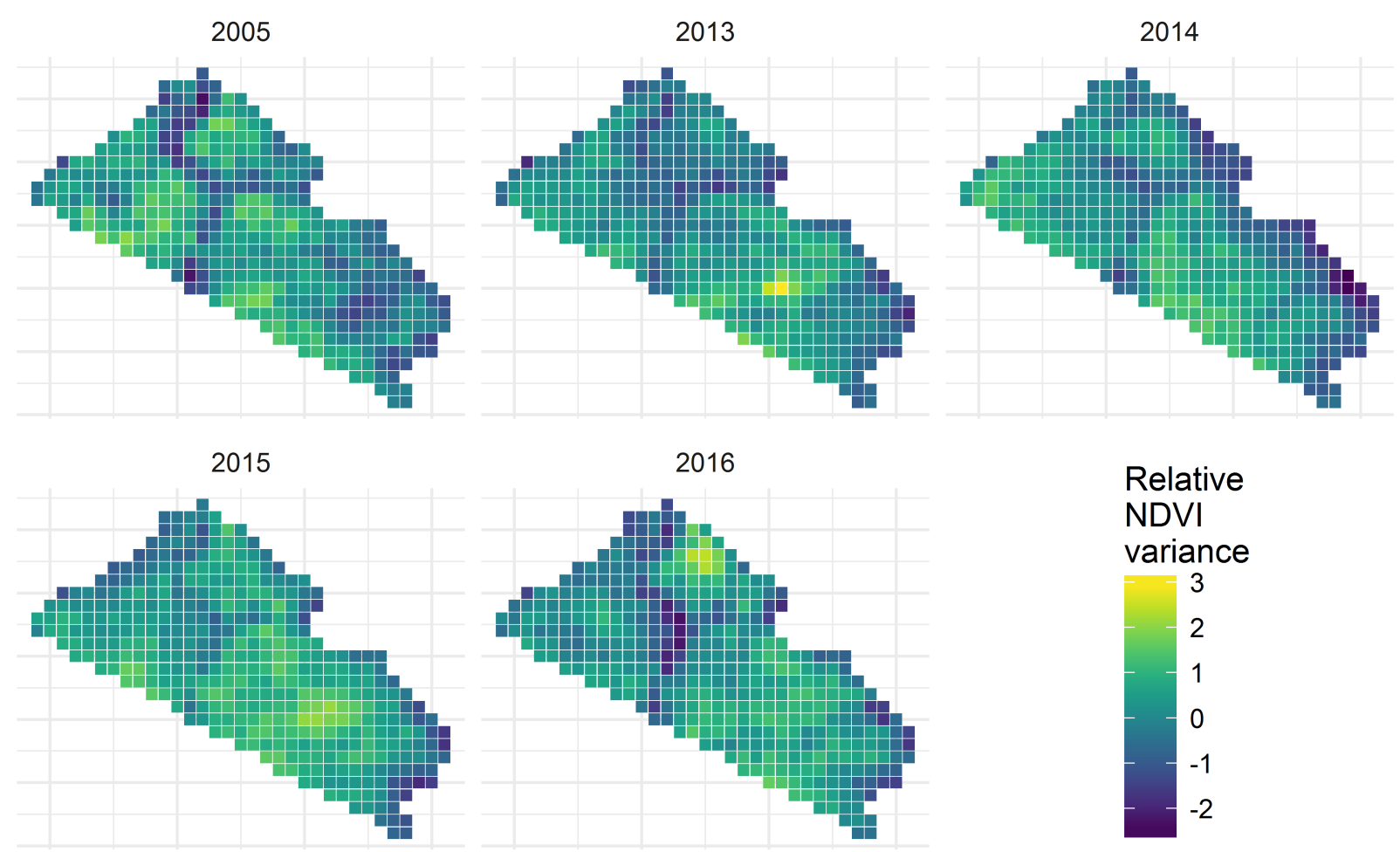